\title{
Environmental Housing and Duration of Exposure Affect Striatal Graft Morphology in a Rodent Model of Huntington's Disease
}

\author{
Máté D. Döbrössy*† and Stephen B. Dunnett* \\ *Brain Repair Group, School of Biosciences, Cardiff University, Cardiff CF10 3US, UK \\ $\dagger$ Laboratory of Molecular Neurosurgery, Universitätsklinikum Freiburg, 79106 Freiburg, Germany
}

\begin{abstract}
Clinical trials of cell replacement therapy in Huntington's disease have shown its safety, feasibility, and potentially long-lasting effects. However, more needs to be known regarding the conditions that stimulate plasticity and compensation achieved by neural grafts to maximize posttransplantation recovery of such neurorehabilitative therapies. The effects of enriched environment (EE), behavioral experience, and transplantation can each separately influence neuronal plasticity and recovery of function after brain damage, and the mechanisms by which these factors interact to modify the survival, integration, or function of grafted tissues are at present unknown. To investigate the effects of variable housing conditions and duration on morphological and cellular changes within embryonic striatal transplants, rats received unilateral excitotoxic lesions of the striatum, followed by E15 whole-ganglionic eminence suspension grafts. The rats were divided into three groups according to housing: full-time EE, $1 \mathrm{~h}$ /day exposure to EE, or standard laboratory cages. The experimental design included "early" ( 7 weeks postgrafting) and "late" (13 weeks postgrafting) survival time points to explore the effects of exposure lengths to the three housing conditions. The morphological and cellular effects on the grafts were analyzed using immunohistochemistry, cell morphology, image analysis, and enzyme-linked immunoassay. Both the duration of the exposure and the housing conditions were seen to influence multiple parameters of grafted cell morphology. The factors acted either independently (e.g., on graft size), complementarily (e.g., on spine density), or had no distinctive effect (e.g., on lesion size) on graft development. Features of embryonic striatal grafts and their trophic milieu were influenced both by the complexity of the environmental conditions and by the length of exposure to them. The data suggest that neurorehabilitation should be a feature of clinical trials of cell transplantation in order to exploit the underlying mechanisms that promote anatomical integration of the grafted cells and maximize transplantmediated functional recovery.
\end{abstract}

Key words: Environmental enrichment; Striatal grafts; Huntington's disease; Rat

\section{INTRODUCTION}

Transplanted striatal cells in the damaged striatum can serve as the substrate for reversing behavioral deficits, including both motor and cognitive impairments, arising following excitotoxic damage of the medium spiny neurons of the striatum $(7,17,22)$. Studies over the past decade investigating the grafting of embryonic striatal tissue into rodent models of neurodegenerative disease then provided the basis for translating this experimental approach into clinical trials of cell replacement therapy aimed at treating Huntington's disease [for review see (13)]. Evidence is now accumulating to support the safety, feasibility, and potentially long-lasting efficacy of this approach $(2,3,25,29,32)$, although other trials have raised reasons for caution (20).
"Environmental enrichment" does not have an agreed definition, but is commonly used to refer to laboratory housing that goes beyond the fundamental requirements of animal welfare by offering complex and stimulating conditions that are more conducive to natural behavior, social interaction, and play than are available to animals in standard laboratory housing conditions. Since Hebb's and Rosenzweig's early experiments $(21,30,31)$, many others have confirmed that enriched environment can affect numerous parameters associated with the mammalian brain, such as cortical thickness, weight, and neuronal transmitter activity (34). More recently, it has been demonstrated that not only can the environment influence the "endogenous" brain tissue, but that environmental enrichment can be the conduit of morphological and cellular changes within embryonic striatal grafts

Received November 20, 2007; final acceptance May 28, 2008.

Address correspondence to Dr. Máté D. Döbrössy, Stereotactic Neurosurgery, Laboratory of Molecular Neurosurgery, Universitätsklinikum Freiburg, Breisacher Str. 64, 79106 Freiburg, Germany. Tel.: (+49) 0761/270-5036; Fax: (+49) 0761/270-9303; E-mail: mate.dobrossy@uniklinikfreiburg.de 
transplanted into the adult brain $(8,10,12,14,18,24)$. Three particular areas associated with graft plasticity were examined in an earlier study: changes in the dendritic spine density of the grafted striatal neurons; changes in neuronal cell volume of the grafted and intact striatal neurons; and changes in brain-derived neurotrophic factor levels in various CNS regions (12). The examined features, associated with function, plasticity, and graft integration, have been shown to be sensitive to external influences during the posttransplantation period.

One of the simplest ways of enhancing the behavioral experiences of laboratory animals is to allow for greater opportunities for sensory and motor stimulation, activity, social interaction, and exploration of the environment than is provided by conventional housing. However, neither the duration nor the nature of the exposure to the enriched environment necessary to observe changes in graft plasticity is known. In the current study, using a rodent model of Huntington's disease, we compared continuous enrichment, daily 1 -h exposure to enrichment, with standard housing conditions and describe the influence the differential housing conditions had on cellular and morphological indices of graft plasticity at a short-term and a long-term graft survival time. The results suggest that the features of embryonic striatal grafts and their trophic milieu are influenced both by the complexity of the environmental conditions and by the length of exposure to them. In the future, neurorehabilitation should become a feature of clinical trials of cell transplantation in Huntington's disease aiming to exploit the underlying mechanisms promoting anatomical integration of the grafted cells and thereby maximizing transplant-mediated functional recovery.

\section{MATERIALS AND METHODS}

The experimental groups and design are summarized in Table 1 and Figure 1, respectively.

\section{Subjects}

Sixty-four male Sprague-Dawley rats (Harlan, Bicester, UK) were used in the experiment. They weighed

Table 1. Experimental Groups

\begin{tabular}{llc}
\hline Housing Conditions & Time & No. \\
\hline Enriched environment full-time & early & 11 \\
Enriched environment 1 h/day & early & 11 \\
Standard full-time & early & 11 \\
Enriched environment full-time & late & 11 \\
Enriched environment 1 h/day & late & 10 \\
Standard full-time & late & 10 \\
\hline
\end{tabular}

approximately $250 \mathrm{~g}$ on arrival and were housed in standard laboratory cages with four rats per cage at the start of the experiment and until surgery. The standard cages had sawdust covered floors, a single cardboard tube, and were cleaned once a week. The temperature throughout the animal house was controlled at $21^{\circ} \mathrm{C}$ and the humidity was kept at a constant $50 \%$. The rats were kept on a 12-h/12-h light/dark cycle (lights on at $0800 \mathrm{~h}$ ). Food and water were freely available to the animals throughout the experiment. The study was undertaken in accordance with local ethical review and licences under the UK Animals (Scientific Procedures) Act 1986.

\section{Differential Housing}

After lesion and grafting, 21 rats remained in standard cages, 22 were moved to enriched cages housing 11 rats per cage, and 21 were housed in standard cages for the majority of the time but spent $1 \mathrm{~h}$ per day in enriched cages, 11 rats in one cage and 10 in the other. The enriched cages were $90 \mathrm{~cm}$ (width) $\times 70 \mathrm{~cm}$ (depth) $\times 65$ $\mathrm{cm}$ (height) and contained two cardboard tubes, a large dark area, and a horizontal balance bar (8).

\section{Lesion Surgery}

Rats were anesthetized by inhalation anesthetic (Isoflurane, Abbott, Maidenhead, UK) and placed in a stereotaxic frame (model 900, Kopf Instruments, Tujunga, USA). The striatum was lesioned unilaterally by injecting $0.25 \mu \mathrm{l}$ of $0.12 \mathrm{M}$ quinolinic acid (Cambridge Research Biochemicals, Cambridge, UK) dissolved in 0.1 $\mathrm{M}$ phosphate-buffered saline (PBS), at two depths in each of two tracks in the left neostriatum. The infusions were made over $90 \mathrm{~s}$ via a 30-gauge stainless steel cannula connected to a microdrive pump, with 2 min allowed for diffusion; coordinates were $\mathrm{A}=-0.4 ; \mathrm{L}=3.5$; $\mathrm{V}=5.0$ and $4.0 \mathrm{~mm}$; and $\mathrm{A}=1.0 ; \mathrm{L}=2.9 ; \mathrm{V}=5.0$ and $4.0 \mathrm{~mm}$, with the nose bar set $-2.3 \mathrm{~mm}$ below the interaural line. Prior to regaining consciousness, animals received $5 \mathrm{ml}$ glucose saline SC and $0.15 \mathrm{ml}$ diazepam IM (Roche, UK; $5 \mathrm{mg} / \mathrm{ml}$ ). Paracetemol analgesic (1 g/L) was added to the drinking water for $48 \mathrm{~h}$ after surgery.

\section{Graft Surgery}

Ten days after lesion, graft tissues were dissected from E15 rat embryos (crown rump length: $12 \mathrm{~mm}$ ) harvested by cesarean section from pregnant SpragueDawley dams. The embryonic brains were removed and the whole embryonic ganglionic eminence was dissected and collected in glucose-buffered saline. Tissue pieces were pooled from all embryos of the litter, incubated in $0.1 \%$ bovine pancreatic trypsin (Worthington, Lakewood, NJ, USA), washed, and prepared as dissociated cell suspensions as previously described (15). The cells 


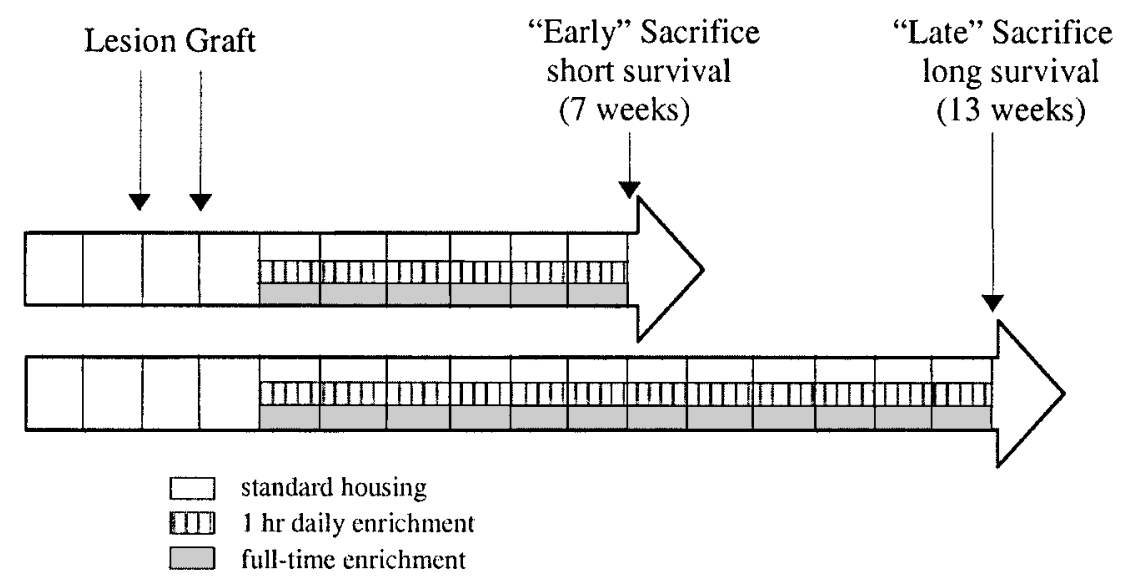

Figure 1. Experimental treatments.

were transfected with an equine lentivirus expressing LacZ (Oxford Biomedica, UK). The volume of virus required for the transfection was calculated by taking account of the total number of cells available in the suspension, the multiplicity of infection factor $(\mathrm{MOI}=2)$, and the virus titer $\left(2 \times 10^{6}\right)$. On completion of the preparation of the single-cell suspension the cells were resuspended in a total volume $100 \mu \mathrm{l}$ of dissection medium, including the volume of virus required. The cells were incubated with the virus at $37^{\circ} \mathrm{C}$ for $60 \mathrm{~min}$, spun down at $2000 \mathrm{rpm}$ for $3 \mathrm{~min}$, and washed with $0.5 \mathrm{ml} \mathrm{dissec}$ tion medium. Centrifugation and washing steps were repeated twice again with the cells final resuspension in the required volume of $0.05 \%$ DNase solution (Sigma, Poole, UK) ready for transplantation. Cell viability was assessed by trypan blue exclusion in a hemocytometer to be $>98 \%$ viability, and suspension volumes were adjusted to yield a cell concentration of 200,000 cells $/ \mu l$. Host animals were again anesthetized using isoflurane and positioned in the stereotaxic frames. The cell suspension was injected via a $10-\mu l$ glass microsyringe with wide bore needle (SGE, Ringwood, Australia) targeted at $\mathrm{A}=0.3 ; \mathrm{L}=3.2 ; \mathrm{V}=4.8$ and $4.2 \mathrm{~mm}$, with the nose bar set $-2.3 \mathrm{~mm}$ below the interaural line. A volume of $1 \mu \mathrm{l}$ was injected over $2 \mathrm{~min}$ at each of the two depths ( $\sim 400,000$ cells/graft), with a further 3 min allowed for diffusion before retraction of the cannula and suturing the wound. Prior to regaining consciousness, animals received $5 \mathrm{ml}$ glucose saline SC. Paracetemol analgesic $(1 \mathrm{~g} / \mathrm{L})$ was added to the drinking water for $48 \mathrm{~h}$ after surgery.

\section{Histology and Image Analysis}

Following differential housing treatment, the majority of rats were injected with a 2-ml lethal dose of Eu- thatal (pentobarbital sodium; Vericore Ltd, Dundee, UK), and were transcardially perfused with $100 \mathrm{ml} 0.9 \%$ saline followed by $250 \mathrm{ml} 4 \%$ paraformaldehyde in 0.1 M PBS ( $\mathrm{pH} 7.4$ ). The brains were removed and postfixed overnight in $4 \%$ paraformaldehyde. The following day they were immersed in $30 \%$ sucrose in PBS until they sank. Serial sections were cut on a freezing stage microtome at $40 \mu \mathrm{m}$. Sections were stained free floating in 1:6 series immunohistochemically by the streptavidinbiotin method (DAKO, Denmark) with 3,3'-diaminobenzidine as chromagen, using the following primary antibodies: NeuN, as a marker of mature neurons (1:4000, Chemicon); the 32-kDa dopamine and adenosine $3^{\prime}: 5^{\prime}$ monophosphate regulated protein, DARPP-32, a marker of striatal projection neurons (1:30000, donated by Prof. Hemmings, Cornell University); and tyrosine kinase B (TrkB), the BDNF receptor (1:2000, Chemicon). The Vector(C) SG method was used with free-floating sections to stain for $\beta$-galactosidase $(\beta-\mathrm{Gal})$ to identify grafted cells infected with the LacZ lentivius (1:6000, Chemicon). Double labeling was undertaken for DARPP32 and TrK B receptors, DARPP-32 and NeuN, using TMB One Solution as the second chromogen.

The volumes and extent of the grafts and lesions were measured with a Leitz Dialux 22 light microscope using Scion image analysis package on stained serial sections. In the NeuN and DARPP-32 sections the outline of the remaining striatum, the lesion, and the graft were traced. Five sections covering the cross section of the entire graft were used to calculate the volumes. The equation used was: volume $\left(\mathrm{mm}^{3}\right)=$ sum of areas $\times$ section thickness $(40 \mu \mathrm{m}) \times$ frequency of section $(1$ in 6 or 1 in 12$)$. NeuN stains all mature neurons irrespective of phenotype. DARPP-32 stains striatal neurons specifically within the heterogeneous graft, allowing discrimination 
between the striatal-like areas, thought to be functionally important, and the nonstriatal areas (19).

\section{DARPP-32 Cell Volumes}

Stereological measurements were undertaken using an Olympus BX-2 microscope with motorized stage, connected to a computer with the CAST-GRID software (Olympus). DARPP-32 cell volumes were estimated by the optical dissector method using unbiased sampling at a magnification of $100 \times$; 60 cells from the medial contralateral (intact) striatum and 60 cells from the graft were measured per section.

\section{Spine Density Analysis}

The same stereology system was used to analyze the density of dendritic spines in sections from grafted animals stained for $\beta$-Gal (1:2000) with NeuN (1:4000) and DARPP-32 (1:30000). The grafted tissue was previously transfected with LacZ; therefore, $\beta-$ Gal localized to the grafted tissue and was present in the dendrites themselves and also in the dendritic spines and shafts. Unbiased sampling at $100 \times$ magnification was used to analyze an average of $20 \beta$-Gal-positive dendrites within the grafted area of each animal. Spine density was calculated as the number of spines per unit length of dendrite.

\section{Enzyme-Linked Immunosorbent Assay (ELISA)}

The remaining five rats from each of the housing conditions for both survival periods were taken and injected with a lethal dose of Euthatal (pentobarbital sodium), decapitated, and their brains were removed. Tissue was dissected bilaterally from dorsal striatum, the hippocampus, the cerebellum, and the cortex on ice, and stored at $-80^{\circ} \mathrm{C}$ in preweighed Eppendorf tubes, and the weight of each dissected tissue piece determined.

Three of the animals for each of the housing conditions for both the early and late time period were taken. The levels of the neurotrophic factor BDNF in each sample were measured using the ELISA method $\left(\mathrm{E}_{\max }\right.$ ImmunoAssay System; Promega, Madison, WI, USA). The samples were homogenized, centrifuged, and the supernatant fluid containing extracted BDNF was pipetted, in duplicate, into a 96-well plate that had been precoated with anti-BDNF monoclonal antibody. Nonspecific binding was reduced by blocking and antihuman polyclonal antibody and was incubated with the extracted BDNF. Anti-IgY conjugated with horseradish peroxidase antibody was used to detect the polyclonal antibody specifically bound to the BDNF. The horseradish peroxidase antibody results in a color change proportional to the amount of BDNF present when incubated with a chromogenic substrate. The absorbance of the test samples were compared to the absorbance of standard BDNF samples of known concentrations. A microplate reader at $450 \mathrm{~nm}$ wavelength was used to read the absorbance of the color development. As the sample concentrations were obtained in duplicate, the mean value was analyzed.

\section{Statistics}

Statistical analysis was undertaken on all quantitative measurements by multifactorial analyses of variance (Genstat 9.1, Lawes Agricultural Project, Rothampsted, UK), with post hoc comparisons undertaken using Newman-Keuls test to identify the source of significant main effects and interactions (critical difference, $p=0.05$ ).

\section{RESULTS}

The anatomical, morphological and BDNF data are summarized in Table 2.

\section{Anatomical Measurements}

Large surviving grafts were seen in all animals. The grafts were rich in NeuN neurons throughout the graft mass (Fig. 2B), and contained patches of DARPP-32 rich "P zones" interspersed with areas of low DARPP32 staining (Fig. 2D), directly comparable to previous descriptions of similar preparations $(11,16,19)$.

NeuN, a mature neuronal marker stain, was used to identify the boundaries of the intact and the lesioned striatum, the extent of the lesion, and the grafted tissue. The quinolinic acid injected unilaterally into the dorsal striatum resulted in similar amounts of cell loss across all groups independent of the housing or survival times. The cell loss and atrophy in the lateral striatum extended medially and caudally, and the NeuN staining showed loss of all cells of neuronal morphology, including both medium and large cells. Striatal neuropil collapse caused by the lesion was suggested by the enlargement of the lateral ventricle on the lesioned side. The lesion, quantified as the difference in volume between the intact (contralateral) and the affected (ipsilateral) striatum, reduced the surviving striatal volume to approximately $26 \pm 2 \%$ of the intact side, and was of comparable extent in all three housing conditions at both survival times (Table 2; all differences, n.s.).

The grafted cells within the lesioned striatum were visualized using NeuN and DARPP-32 staining. NeuN staining demonstrated good graft survival in the host striatum, and the presence of many cells of neuronal morphology within the transplant (Fig. 2A, B). Volumetric measurements of the grafts indicated larger transplants in those animals that were kept under full-time enriched conditions [Housing, $F(2,41)=3.90, p<0.05$; post hoc Neuman-Keuls test, EE-FT $>$ pEE-1 h $=$ Std], with survival time having no significant effect $[F(1,41)=$ 0.04, n.s.] (Table 2).

DARPP-32 staining was used to visualize striatal-like 
Table 2. Anatomical, Morphological, and BDNF Data

\begin{tabular}{|c|c|c|c|c|c|c|}
\hline \multirow[b]{2}{*}{ Measurement } & \multirow[b]{2}{*}{ Unit } & \multirow[b]{2}{*}{ Time } & \multirow{2}{*}{$\begin{array}{l}\text { Standard } \\
\text { Full-Time }\end{array}$} & \multicolumn{2}{|c|}{ Enriched Environment } & \multirow[b]{2}{*}{ Comments } \\
\hline & & & & $1 \mathrm{~h} /$ Day & Full-Time & \\
\hline \multicolumn{7}{|l|}{ Lesion/graft anatomy } \\
\hline Lesion volume & $\mathrm{mm}^{3}$ & early & $9.2 \pm 0.9$ & $12.3 \pm 0.9$ & $12.0 \pm 0.5$ & \multirow[t]{2}{*}{ No clear pattern } \\
\hline & & late & $12.6 \pm 0.9$ & $9.8 \pm 0.6$ & $12.5 \pm 0.5$ & \\
\hline \multirow[t]{2}{*}{ Graft volume } & $\mathrm{mm}^{3}$ & early & $2.6 \pm 0.4$ & $2.7 \pm 0.4$ & $3.9 \pm 0.3$ & \multirow[t]{2}{*}{ EE FT $>$ Std, EE $1 \mathrm{~h}$} \\
\hline & & late & $3.2 \pm 0.5$ & $2.6 \pm 0.4$ & $3.6 \pm 0.7$ & \\
\hline \multirow[t]{2}{*}{ DARPP-32 patch volume } & $\mathrm{mm}^{3}$ & early & $0.8 \pm 0.1$ & $0.6 \pm 0.1$ & $0.9 \pm 0.1$ & \multirow[t]{2}{*}{ No clear pattern } \\
\hline & & late & $0.6 \pm 0.1$ & $0.8 \pm 0.1$ & $0.7 \pm 0.1$ & \\
\hline \multicolumn{7}{|l|}{ Graft morphology } \\
\hline DARPP-32 cell volume & $\mu \mathrm{m}^{3}$ & early & $433 \pm 14$ & $376 \pm 22$ & $411 \pm 30$ & \multirow[t]{2}{*}{ Late $>$ early } \\
\hline & & late & $420 \pm 12$ & $478 \pm 13$ & $464 \pm 11$ & \\
\hline \multirow[t]{2}{*}{ Spine density } & \multirow[t]{2}{*}{ spines $/ \mu \mathrm{m}$} & early & $0.44 \pm 0.02$ & $0.50 \pm 0.01$ & $0.52 \pm 0.01$ & \multirow{2}{*}{$\begin{array}{l}\text { EE FT, EE } 1 \mathrm{~h}>\text { Std } \\
\text { Late }>\text { early }\end{array}$} \\
\hline & & late & $0.45 \pm 0.01$ & $0.54 \pm 0.02$ & $0.57 \pm 0.01$ & \\
\hline \multicolumn{7}{|l|}{ BDNF ELISA } \\
\hline \multirow[t]{2}{*}{ Grafted striatum } & $\mathrm{pg} / \mathrm{g}$ & early & $6.1 \pm 1.3$ & $4.8 \pm 1.4$ & $5.7 \pm 2.4$ & \multirow[t]{2}{*}{ Late $>$ early } \\
\hline & & late & $11.4 \pm 2.2$ & $12.3 \pm 1.5$ & $7.7 \pm 1.3$ & \\
\hline \multirow[t]{2}{*}{ Contra striatum } & $\mathrm{pg} / \mathrm{g}$ & early & $2.9 \pm 0.2$ & $2.8 \pm 0.5$ & $2.9 \pm 0.4$ & \multirow[t]{2}{*}{ Grafted $>$ contra } \\
\hline & & late & $6.6 \pm 1.0$ & $8.7 \pm 0.5$ & $8.2 \pm 2.4$ & \\
\hline \multirow[t]{2}{*}{ Hippocampus } & $\mathrm{pg} / \mathrm{g}$ & early & $10.3 \pm 1.7$ & $13.2 \pm 4.8$ & $11.1 \pm 0.7$ & \multirow[t]{2}{*}{ Late $>$ early } \\
\hline & & late & $14.9 \pm 1.7$ & $19.6 \pm 2.1$ & $15.9 \pm 1.0$ & \\
\hline \multirow[t]{2}{*}{ Cerebellum } & $\mathrm{pg} / \mathrm{g}$ & early & $5.2 \pm 0.4$ & $7.8 \pm 0.9$ & $6.7 \pm 1.8$ & \multirow[t]{2}{*}{ Control tissue: no change in BDNF } \\
\hline & & late & $6.9 \pm 1.0$ & $6.7 \pm 1.1$ & $6.8 \pm 1.3$ & \\
\hline
\end{tabular}

Effects of variable length exposure to different housing conditions on striatal lesion and striatal grafted brains. EE FT, enriched environment fulltime; EE 1 h, enriched environment 1 h/day; Std, standard.

projection neurons within the graft, and in accord with previous description the staining was characteristically patchy in appearance (Fig. 2C, D). Neither housing nor graft survival had significant effects on the volume of the DARPP-32 patches within the grafts (Table 2; all comparisons, n.s.).

\section{Morphological Measurements}

The volumes of DARPP-32-positive neuronal cell bodies were estimated using unbiased stereological methods. DARPP-32 cell volumes were greater in the grafts of longer survival time $[F(1,41)=9.38, p<0.05]$ (Table 2 ), and whereas there was no overall effect on housing conditions as a main effect $[F(2,41)=0.28, p=$ $0.76]$, the increase in cell volumes at longer survival times was more marked in the animals housed under either $1 \mathrm{~h}$ or constant enrichment in contrast to little change in the standard housing condition [Housing $\times$ Survival, $F(2,41)=4.60, p<0.05]$ (Table 2). A comparison of the grafted cells with volumes of DARPP-32 striatal neurons on the intact (contralateral) side indi- cated that the transplanted neurons had larger cell bodies overall [Sides, $F(1,41)=20.39, p<0.05$ ].

Dendritic spines of cells were visualized by staining for $\beta$-Gal, the enzyme coded for by the LacZ gene present in the transfected grafted cells only (Fig. 3). The density of spines distributed on the dendrites of grafted cells was greater in animals housed under enriched conditions, both full-time or $1 \mathrm{~h}$ per day, than if kept in standard cages [House, $F(2,41)=39.02, p<0.001$; post hoc Newman-Keuls test, EE-FT $=$ EE-1 h) $($ Table 2). Furthermore, the spine density of transplanted cells increased in animals with longer survival times [Time, $F(1,41)=13.02, p<0.001]$ (Table 2).

\section{Brain-Derived Neurotrophic Factor (BDNF) Measurements}

BDNF protein levels were measured using enzymelinked immunosorbent assay (ELISA) in sample tissue taken from the ipsilateral and contralateral striatum, hippocampus, and cerebellum for each of the housing conditions. Across all housing conditions and survival 


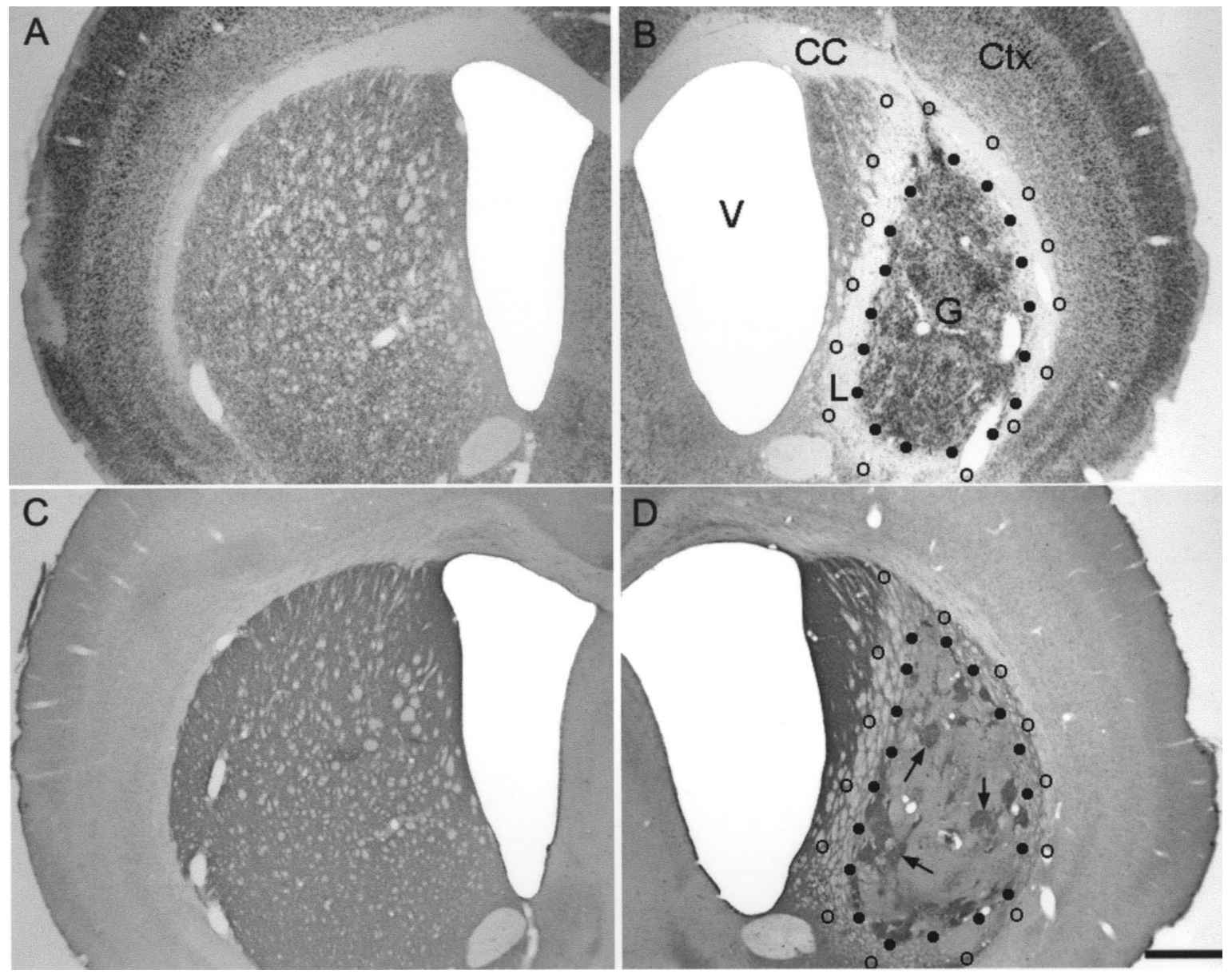

Figure 2. Photomicrographs showing intact and grafted striatum stained with NeuN, a neuron-specific stain (A, B) and DARPP32 , a marker of striatal-like tissue (C, D). The open circles delineate the border of the lesion (seen as the absence of staining within the striatum), while the black dots demark the outer areas of the graft. On the DARPP-32-stained sections, the arrows indicate patches of striatal-like tissue within the grafts. Enlarged ipsilateral ventricles are due to the striatal neuronal loss brought on by the lesioning. The histology was carried out 13 weeks postgrafting. CC, corpus callosum; Ctx, cortex; V, ventricle; L, lesion; G, graft. Scale bar: $1 \mathrm{~mm}$.

times, striatal BDNF levels were higher on the ipsilateral side receiving the lesion and subsequent graft than on the intact contralateral side [Sides, $F(1,12)=12.91, p<$ 0.05]. Also, under all conditions, animals with longer survival times had increased amount of striatal BDNF [Time, $F(1,12)=28.22, p<0.001]$ (Table 2), whereas the housing condition was not a significant factor [Housing, $F(2,12)=0.40$, n.s.]. Hippocampal BDNF levels were similarly higher at the longer survival times, but not to housing environment [Time, $F(1,12)=7.3, p<$ 0.05 ; Housing, $F(2,12)=1.37$, n.s.] (Table 2). Cerebellar BDNF levels were insensitive to both independent variables [Housing, $F(2,12)=0.56, p=0.59$; Survival, $F(1,12)=0.09$; both n.s.] (Table 2) and hence may be considered as a control tissue. Correspondingly, Figure 4 illustrates the BDNF target TrkB receptor staining in the hippocampus, intact striatum, and transplanted stria- tum, but not in the lesioned striatum (or indeed in cerebellum, not shown).

\section{DISCUSSION}

Previous studies have shown that exposure to continuous long-term environmental enrichment following transplantation of embryonic striatal tissue into the adult striatum in rodent models of Huntington's disease can influence morphological and cellular features of grafts $(10,12)$. However, the nature of the enrichment-in terms of the length of time and exposure schedule required to affect graft plasticity-has not been investigated. We show that both the survival time and the differential housing conditions can influence the morphological development of striatal-like neurons within striatal transplants. The results also indicate that both the duration of the exposure and the housing conditions can 
influence the trophic milieu, suggesting a mechanism for their influence on the morphological development of transplanted cells.

Enriched environment has been shown to influence cellular, molecular, and behavioral processes in wildtype, transgenic, and numerous other animal models of neurodegenerative disease $(8,28,34)$. However, the experimental condition widely referred to as "enrichment" is not fully defined in terms of the complexity of the housing experience, of how long the exposure needs to last, or of the nature of the animal's interaction with its environment, in order to observe the effects. Generally, enriched environment is described as long-term exposure to increased social interaction, and to a larger and more complex living space. Several of the elements of enrichment responsible for the range of observed cellular and behavioral changes, such as increased locomotor activity associated with greater neurogenesis (33), have been identified, but overall, the state of enrichment and the mechanisms underpinning its influence on the brain are only now beginning to emerge (28).

In the current study, anatomical, morphological, and trophic parameters associated with neuronal plasticity were altered by environmental enrichment. The effects were variable with the outcome depending on housing conditions, duration of exposure, and length of time the graft remained in situ. Furthermore, the factors acted both independently and complementarily on the cellular factors but had only modest influence on overall graft volume and development. Grafted animals in full-time enrichment, independent of whether they survived 7 or 13 weeks, had the largest grafts in the study, but this did not translate into differential survival or expansion of the DARPP-32-positive patches - the functionally relevant striatal-like cells within the grafts (16). Graft volumes from animals housed in standard cages or receiving 1-h daily exposure to enrichment were comparable. The survival of striatal tissue is generally very good in the experimental model of Huntington's disease used, and all animals exhibited good graft survival irrespective of the housing conditions. The observed volumetric differences are therefore most likely to be due to differences in internal organization of the cells within the graft (as suggested by larger cell volumes and higher

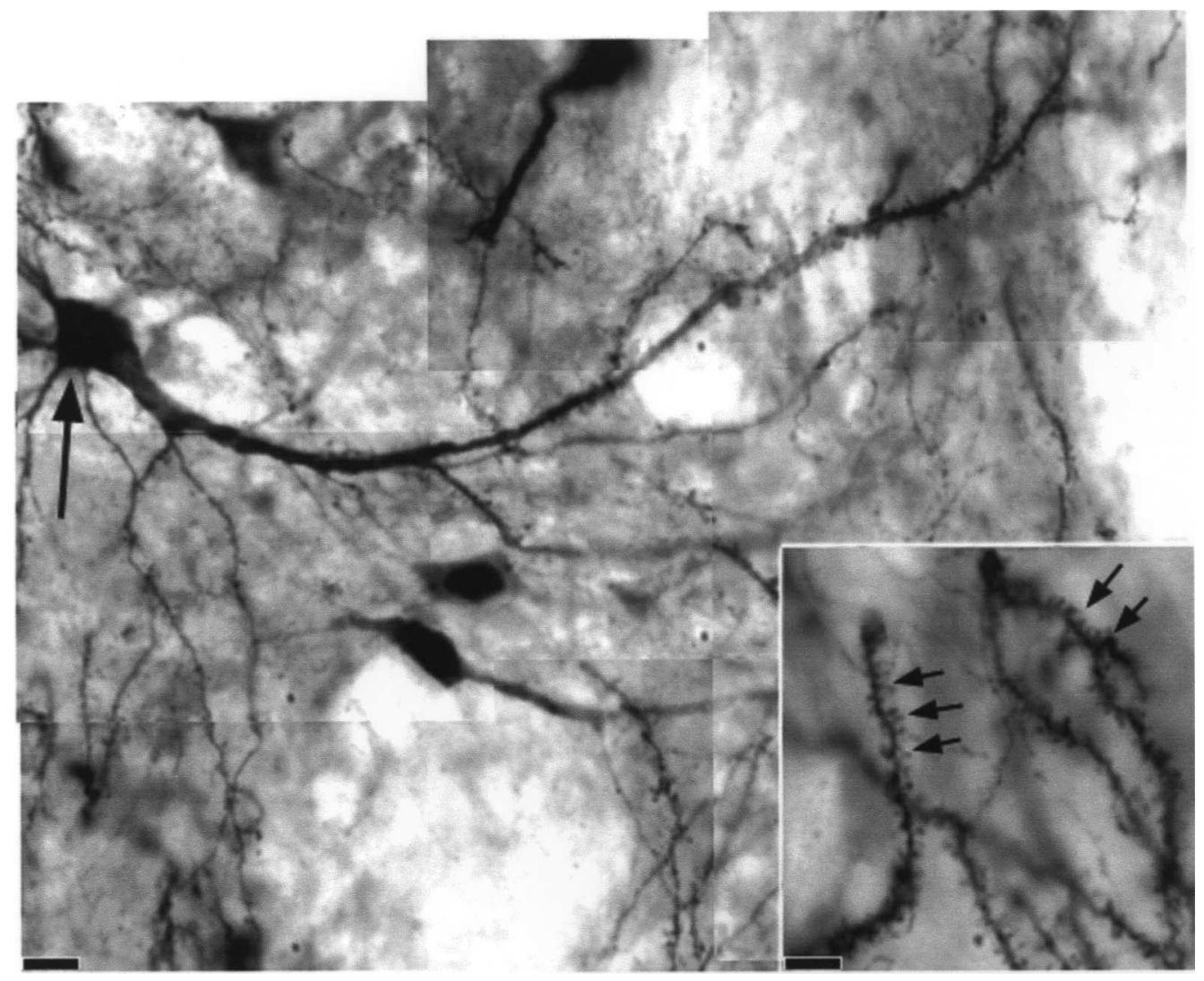

Figure 3. Photomicrographs of $\beta$-galactosidase-stained neurons, with dendritic spines and shafts, from within the graft. The arrows point out grafted neurons and their dendritic spines, which can be seen clearly, perpendicular to the shaft of the dendrite. Scale bar: $10 \mu \mathrm{m}$ (inset $4 \mu \mathrm{m}$ ). 

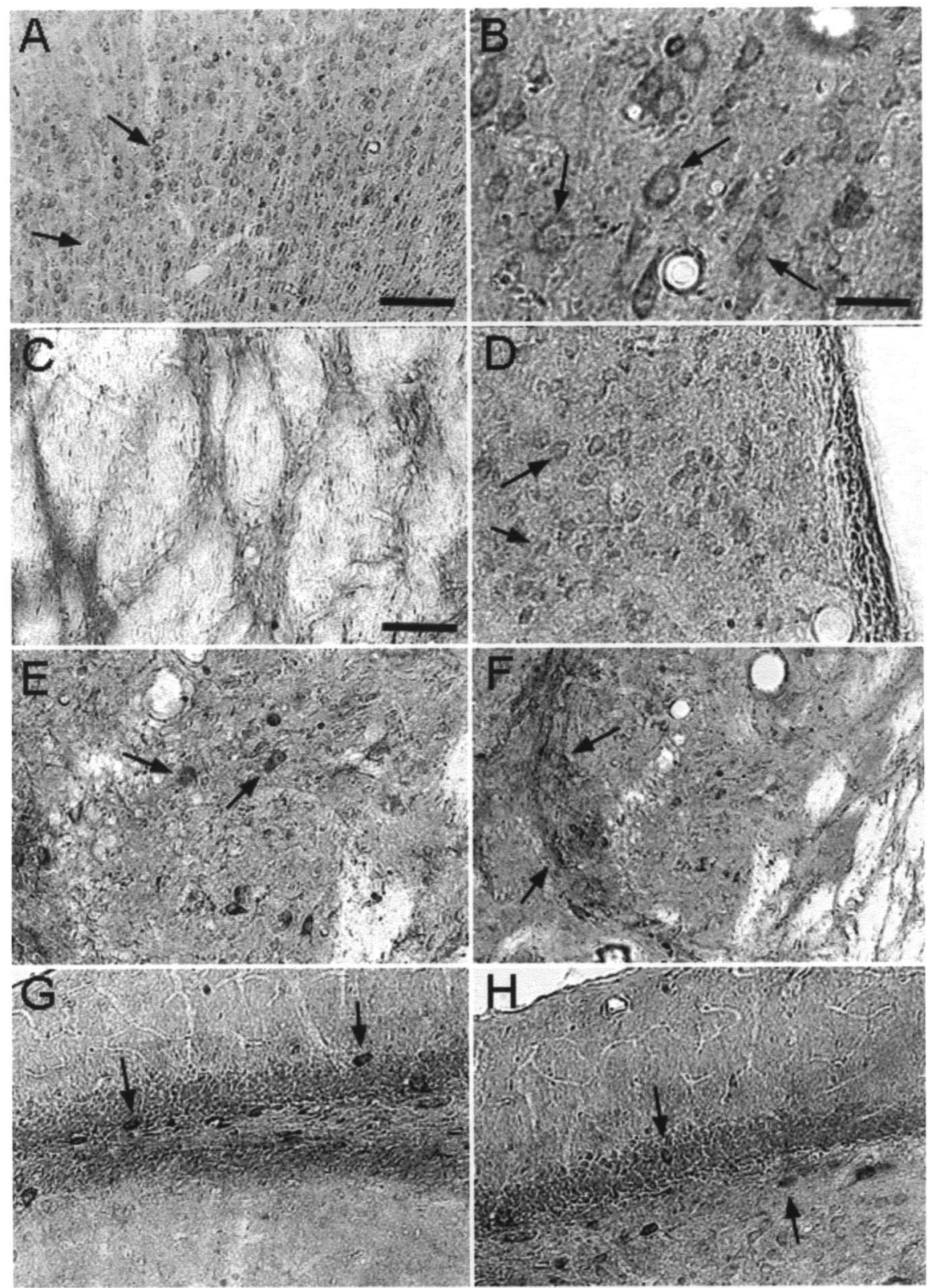

Figure 4. Photomicrographs showing TrkB receptor staining (the receptor for BDNF). Cortex (A, B) stains well for TrkB. Within the lesioned striatum, due to neuronal loss, staining is absent (C), and this becomes apparent when examining the normal levels of TrkB staining seen in an intact striatum (D). Importantly, TrkB was also expressed within the striatal transplants (E, F), albeit less so compared to the intact striatum. Hippocampus shows high levels of staining for TrkB receptor. Scale bars: (A) $100 \mu \mathrm{m}$; (B) $20 \mu \mathrm{m}$; (C-H) $50 \mu \mathrm{m}$.

density of synaptic spines on the neurons) rather than to differential cell survival, and is attributable both to experience of the more complex environment and to the longer duration of that exposure.

Analysis of DARPP-32-positive grafted neurons indicated that their cell bodies were, on average, larger following longer survival times. This was specifically the case among the enriched animals, in both the full-time and the 1-h per day subgroups, and suggests an accumulative mechanism. Neuronal cell volume is controlled in a variety ways, including via the regulation of calciumpermeable channels (26). Whether the increase in cell volumes of the grafted neurons observed among the enriched animals reflects increased synaptic activity still needs to be examined in detail, but is supported by recent electrophysiological data from our group showing 
that enrichment facilitated host-graft corticostriatal long-term potentiation [(23) and personal communication with Mazzocchi-Jones]. Interestingly, enrichment did not affect striatal LTP in animals without grafts, demonstrating the potential of external influences in optimizing the plasticity of the embryonic striatal grafts.

Additional support that environmental enrichment promoted graft plasticity was obtained by examining the density of dendritic spines present on the grafted neurons. Dendritic spines are specialized ultrastructures whose numbers can reflect the synaptic activity, degree of anatomical integration, and synaptic connectivity at the level of the observed neuronal network $(6,27)$. Both full-time and 1-h daily exposure to the complex environment resulted in an increase density of spines on the dendritic processes compared to the grafted animals in the standard cages. Furthermore, longer graft survival time resulted in increased spine density compared to shorter survival, suggesting that, with respect to this parameter, length of exposure time and the environment were complementary factors.

Animals that survived to the longer time point also had higher BDNF levels in both the striatum and the hippocampus. Within the striatum itself, BDNF levels were superior on the grafted side compared to the intact side. Because BDNF has been shown to modulate striatal neuron survival, differentiation, and synaptic plasticity $(1,36)$, its role as a direct modulator of graft morphology and plasticity is suggested by the present correlation, and requires further experimental attention. The presence of TrkB receptors on the grafted striatal neurons supports the potential for BDNF to provide an effective substrate for the downstream mechanisms associated with the adaptive changes described in the study.

The present results have direct implications for the effective translation of experimental cell transplantation into clinical application. There are a growing number of studies and reviews supporting the potential benefits of rehabilitation programs for Huntington's disease patients $(5,35)$, and the present data suggest that similar strategies could be particularly beneficial to promoting the functional outcome in current trials of cell transplantation. Demonstrating that the transplanted embryonic tissue is susceptible to environmental manipulation is an essential step towards the integration of a posttransplantation after-care strategy, such as physiotherapy, into the clinical treatment of neurodegenerative diseases. Previous animal studies examining the functional effects of embryonic grafts in experimental models of Huntington's disease have shown that recovery can be dependent on the presence of the grafted tissue in conjunction with specific training protocols (4,9-11). Importantly, these studies suggest that for the graft-associated bene- fits to be optimal the treatment needs to go beyond the state of cell replacement and involve additional conditions that promote graft plasticity and the functional integration of the transplant in the host's neuronal circuitry (8). The implication from our data is that enrichment, short or long term, brief or continuous, can help to create an environment favorable for graft-mediated repair. Enriched environment, experience, and transplantation can separately influence neuronal plasticity and recovery of function after brain damage; but the mechanisms by which these factors interact, so that they modify the integration or function of grafted tissues, are at present unresolved. Consequently, more needs to be known regarding the specific features of the environment and the animal's interaction with it that stimulate plasticity and compensation of the grafted tissues, if we are to be optimize designing the most effective rehabilitation strategy to maximize posttransplantation recovery.

In conclusion, features of embryonic striatal grafts and their trophic milieu are influenced both by the complexity of the environmental conditions and by the length, frequency, and duration of such exposure. These results suggest that effective neurorehabilitation should be a feature of future clinical trials of cell transplantation in Huntington's disease to exploit appropriately the underlying mechanisms that promote anatomical integration of the grafted cells and maximize transplant-mediated functional recovery.

ACKNOWLEDGMENTS: We thank Professor Hemmings (Cornell University, USA) for the supply of DARPP-32 antibodies and Sara McPhee for assisting with the data collection. There are no conflicts of interests. The study was funded by a program grant of the UK Medical Research Council.

\section{REFERENCES}

1. Alonso, M.; Bekinschtein, P.; Cammarota, M.; Vianna, M. R.; Izquierdo, I.; Medina, J. H. Endogenous BDNF is required for long-term memory formation in the rat parietal cortex. Learn. Mem. 12:504-510; 2005.

2. Bachoud-Levi, A. C.; Gaura, V.; Brugieres, P.; Lefaucheur, J. P.; Boisse, M. F.; Maison, P.; Baudic, S.; Ribeiro, M. J.; Bourdet, C.; Remy, P.; Cesaro, P.; Hantraye, P.; Peschanski, M. Effect of fetal neural transplants in patients with Huntington's disease 6 years after surgery: A long-term follow-up study. Lancet Neurol. 5: 303-309; 2006.

3. Bachoud-Levi, A. C.; Remy, P.; Nguyen, J. P.; Brugieres, P.; Lefaucheur, J. P.; Bourdet, C.; Baudic, S.; Gaura, V.; Maison, P.; Haddad, B.; Boisse, M. F.; Grandmougin, T.; Jeny, R.; Bartolomeo, P.; Dalla, B. G.; Degos, J. D.; Lisovoski, F.; Ergis, A. M.; Pailhous, E.; Cesaro, P.; Hantraye, P.; Peschanski, M. Motor and cognitive improvements in patients with Huntington's disease after neural transplantation. Lancet 356:1975-1979; 2000.

4. Brasted, P. J.; Watts, C.; Robbins, T. W.; Dunnett, S. B. Associative plasticity in striatal transplants. Proc. Natl. Acad. Sci. USA 96:10524-10529; 1999.

5. Busse, M. E.; Rosser, A. E. Can directed activity improve 
mobility in Huntington's disease? Brain Res. Bull. 72: 172-174; 2007.

6. Comery, T. A.; Stamoudis, C. X.; Irwin, S. A.; Greenough, W. T. Increased density of multiple-head dendritic spines on medium-sized spiny neurons of the striatum in rats reared in a complex environment. Neurobiol. Learn. Mem. 66:93-96; 1996.

7. Dobrossy, M. D.; Dunnett, S. B. Striatal grafts alleviate deficits in response execution in a lateralised reaction time task. Brain Res. Bull. 47:585-593; 1998.

8. Dobrossy, M. D.; Dunnett, S. B. The influence of environment and experience on neural grafts. Nat. Rev. Neurosci. 2:871-879; 2001.

9. Dobrossy, M. D.; Dunnett, S. B. Motor training effects on recovery of function after striatal lesions and striatal grafts. Exp. Neurol. 184:274-284; 2003.

10. Dobrossy, M. D.; Dunnett, S. B. Environmental enrichment affects striatal graft morphology and functional recovery. Eur. J. Neurosci. 19:159-168; 2004.

11. Dobrossy, M. D.; Dunnett, S. B. Training specificity, graft development and graft-mediated functional recovery in a rodent model of Huntington's disease. Neuroscience 132: 543-552; 2005.

12. Dobrossy, M. D.; Dunnett, S. B. Morphological and cellular changes within embryonic striatal grafts associated with enriched environment and involuntary exercise. Eur. J. Neurosci. 24:3223-3233; 2006.

13. Dunnett, S. B.; Rosser, A. E. Cell therapy in Huntington's disease. NeuroRx 1:394-405; 2004.

14. Dunnett, S. B.; Whishaw, I. Q.; Bunch, S. T.; Fine, A. Acetylcholine-rich neuronal grafts in the forebrain of rats: Effects of environmental enrichment, neonatal noradrenaline depletion, host transplantation site and regional source of embryonic donor cells on graft size and acetylcholinesterase-positive fibre outgrowth. Brain Res. 378:357-373; 1986.

15. Fricker, R. A.; Barker, R. A.; Fawcett, J. W.; Dunnett, S. B. A comparative study of preparation techniques for improving the viability of striatal grafts using vital stains, in vitro cultures, and in vivo grafts. Cell Transplant. 5: 599-611; 1996.

16. Fricker, R. A.; Torres, E. M.; Dunnett, S. B. The effects of donor stage on the survival and function of embryonic striatal grafts in the adult rat brain. I. Morphological characteristics. Neuroscience 79:695-710; 1997.

17. Fricker, R. A.; Torres, E. M.; Hume, S. P.; Myers, R.; Opacka-Juffrey, J.; Ashworth, S.; Brooks, D. J.; Dunnett, $\mathrm{S}$. B. The effects of donor stage on the survival and function of embryonic striatal grafts in the adult rat brain. II. Correlation between positron emission tomography and reaching behaviour. Neuroscience 79:711-721; 1997.

18. Grabowski, M.; Sorensen, J. C.; Mattsson, B.; Zimmer, J.; Johansson, B. B. Influence of an enriched environment and cortical grafting on functional outcome in brain infarcts of adult rats. Exp. Neurol. 133:96-102; 1995.

19. Graybiel, A. M.; Liu, F. C.; Dunnett, S. B. Cellular reaggregation in vivo: modular patterns in intrastriatal grafts derived from fetal striatal primordia. Prog. Brain Res. 82: 401-405; 1990.

20. Hauser, R. A.; Furtado, S.; Cimino, C. R.; Delgado, H.; Eichler, S.; Schwartz, S.; Scott, D.; Nauert, G. M.; Soety, E.; Sossi, V.; Holt, D. A.; Sanberg, P. R.; Stoessl, A. J.; Freeman, T. B. Bilateral human fetal striatal transplantation in Huntington's disease. Neurology 58:687-695; 2002.
21. Hebb, D. O. The organization of behaviour: A aeuropsychological theory. New York: Wiley; 1949.

22. Isacson, O.; Dunnett, S. B.; Bjorklund, A. Graft-induced behavioral recovery in an animal model of Huntington disease. Proc. Natl. Acad. Sci. USA 83:2728-2732; 1986.

23. Jones-Mazzocchi, D.; Dobrossy, M. D.; Dunnett, S. B. Striatal grafts and synaptic plasticity. In: Bolam, J. P.; Ingham, C. A.; Magill, P. J., eds. Basal ganglia VIII. London: Springer Science and Business Media; 2005:313320.

24. Kelche, C.; Roeser, C.; Jeltsch, H.; Cassel, J. C.; Will, B. The effects of intrahippocampal grafts, training, and postoperative housing on behavioral recovery after septohippocampal damage in the rat. Neurobiol. Learn. Mem. 63:155-166; 1995.

25. Kopyov, O. V.; Jacques, S.; Lieberman, A.; Duma, C. M.; Eagle, K. S. Safety of intrastriatal neurotransplantation for Huntington's disease patients. Exp. Neurol. 149:97-108; 1998.

26. Lang, F.; Busch, G. L.; Ritter, M.; Volkl, H.; Waldegger, S.; Gulbins, E.; Haussinger, D. Functional significance of cell volume regulatory mechanisms. Physiol. Rev. 78: 247-306; 1998.

27. Leggio, M. G.; Mandolesi, L.; Federico, F.; Spirito, F.; Ricci, B.; Gelfo, F.; Petrosini, L. Environmental enrichment promotes improved spatial abilities and enhanced dendritic growth in the rat. Behav. Brain Res. 163:78-90; 2005.

28. Nithianantharajah, J.; Hannan, A. J. Enriched environments, experience-dependent plasticity and disorders of the nervous system. Nat. Rev. Neurosci. 7:697-709; 2006.

29. Peschanski, M.; Bachoud-Levi, A. C.; Hantraye, P. Integrating fetal neural transplants into a therapeutic strategy: the example of Huntington's disease. Brain 127:12191228; 2004.

30. Rosenzweig, M. R.; Bennett, E. L. Psychobiology of plasticity: Effects of training and experience on brain and behavior. Behav. Brain Res. 78:57-65; 1996.

31. Rosenzweig, M. R.; Bennett, E. L.; Diamond, M. C. Effects of differential environments on brain anatomy and brain chemistry. Proc. Annu. Meet. Am. Psychopathol. Assoc. 56:45-56; 1967.

32. Rosser, A. E.; Barker, R. A.; Harrower, T.; Watts, C.; Farrington, M.; Ho, A. K.; Burnstein, R. M.; Menon, D. K.; Gillard, J. H.; Pickard, J.; Dunnett, S. B. Unilateral transplantation of human primary fetal tissue in four patients with Huntington's disease: NEST-UK safety report ISRCTN no 36485475. J. Neurol. Neurosurg. Psychiatry 73:678-685; 2002.

33. van Praag, H.; Kempermann, G.; Gage, F. H. Running increases cell proliferation and neurogenesis in the adult mouse dentate gyrus. Nat. Neurosci. 2:266-270; 1999.

34. van Praag, H.; Kempermann, G.; Gage, F. H. Neural consequences of environmental enrichment. Nat. Rev. Neurosci. 1:191-198; 2000.

35. Zinzi, P.; Salmaso, D.; De Grandis, R.; Graziani, G.; Maceroni, S.; Bentivoglio, A.; Zappata, P.; Frontali, M.; Jacopini, G. Effects of an intensive rehabilitation programme on patients with Huntington's disease: A pilot study. Clin. Rehabil. 21:603-613; 2007.

36. Zuccato, C.; Cattaneo, E. Role of brain-derived neurotrophic factor in Huntington's disease. Prog. Neurobiol. 81:294-330; 2007. 